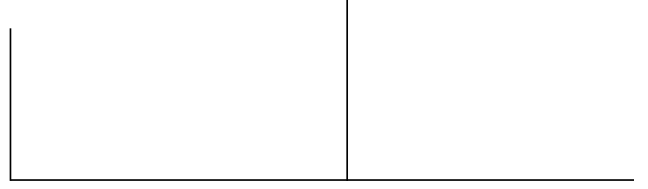

Rev. Latinoam. Psicopat. Fund., VII, 3, 166-170

Dos sons à palavra: explorações sobre o tratamento psicanalítico da criança autista

Maria Izabel Tafuri

Brasília: ABRAFIPP, 2003

\title{
Dos sons à palavra: explorações sobre o tratamento psicanalítico da criança autista
}

Maria Teresa de Melo Canvalho

Com a publicação do livro Dos sons à palavra: explorações sobre o tratamento psicanalítico da criança autista, de Maria Izabel Tafuri, a literatura psicanalítica é enriquecida com um trabalho que tem qualidades suficientes para tornar-se uma referência clássica sobre o autismo infantil.

Fruto de uma pesquisa acadêmica enraizada na prática clínica com crianças portadoras de graves distúrbios psíquicos, esse trabalho reúne, de forma surpreendente, o rigor próprio à academia e a fluidez necessária à clínica. Mostra-nos, em cada página, o passo a passo de uma pesquisadora que examinou minuciosamente os trabalhos que o precederam, ao mesmo tempo em que vai revelando-nos, em sua mensagem mais marcante, o despojamento e o desamparo de uma analista que realmente recusou o lugar do "suposto saber" para escutar sua paciente. Assim, ela abre a possibilidade de uma nova escuta, criando uma forma nova de intervenção na clínica do autismo.

Maria, a pequena paciente que ilustra e dá vida a esse livro, vai transformando-se, através da sensibilidade da autora/analista, e à medida que avança sua reflexão, em mais um caso paradigmático da psicanálise de crianças. Trata-se de uma criança de três anos, que chega à consulta com o diagnóstico de autismo infantil precoce, realizado por uma equipe médica, a pedido da escola que freqüentava. Os pais buscam a avaliação 
de outro profissional, dada a gravidade do caso da filha. Foi o passo que deram para proporcionar à filha a chance de um raro encontro que viria abrir para essa criança a possibilidade de existir como sujeito e como filha desses pais que, por sua vez, poderão vivenciar a experiência de serem reconhecidos como tais: pai e mãe dessa filha. Quanto à analista, esse encontro parece reativar algo da ordem de uma "questão fundamental”, como a entende Piera Aulagnier (1984). Questão que será perseguida com tal afinco que o caráter "avassalador e enigmático" dos primeiros encontros com Maria será contrabalançado pelo seu caráter instigante e fecundo, resultando numa tese inovadora sobre a condução do tratamento da criança autista: a tese do "analista não intérprete".

Toda a tradição da psicanálise de crianças, incluindo aí as experiências de analistas com crianças autistas, ou portadoras de graves transtornos psíquicos, indica o uso da interpretação como forma privilegiada de intervenção. Sendo assim, ao assumir a atitude clínica de "não interpretar”, a analista não somente fica sozinha diante da criança em seu "autismo", sem a mediação da única ferramenta de trabalho de que normalmente dispomos, como também fica só, sem o respaldo da literatura especializada. Não obstante, para sua sustentação, Maria Izabel encontra apoio em dois pilares fundamentais, quais sejam, sua experiência anterior como estagiária na École de Bonneuil, dirigida por Maud Mannoni, onde aprendeu a acompanhar a criança em seu sofrimento, sem tratá-la ou interpretála, e o ensinamento de Winnicott, autor reconhecido pela contribuição decisiva na clínica dos casos em que a análise clássica encontra limites.

O relato da experiência na École Éxperimentale de Bonneuil-sur-Marne é um dos muitos pontos altos desse livro, sendo interessante descobrir que Winnicott esteve presente, também, como fonte de inspiração para o modelo de abordagem de crianças autistas e psicóticas, adotado em Bonneuil, a partir das discussões clínicas mantidas regularmente por Mannoni com o psicanalista inglês, na década de 1960.

Outro ponto que se destaca no primeiro capítulo são as reflexões sobre a relação transferencial que estaria se estabelecendo no início do tratamento. Estas reflexões levaram a analista à conclusão de que deveria esperar o momento em que o material clínico tornasse claro o que interpretar, como ensina Winnicott, em vez de propor interpretações explicativas que lhe brotavam na mente automaticamente como uma forma de defesa contra a impotência vivida no momento da sessão.

Maria havia evitado a analista, pois somente esta não podia ser tocada da forma como eram tocados os móveis, as paredes, os brinquedos e demais objetos da sala. Constatação simples porém suficiente para indicar que "interpretar naquele momento seria o mesmo que tocá-la com palavras” (p. 34). Seria apressado demais, pois até a voz da analista poderia significar uma presença ameaça- 
R E V I S T A

dora. Foi preciso, então, inventar um outro modo de intervir, recorrer a um tipo de conhecimento que não fosse aquele proveniente de interpretações explicativas, mas sim oriundo das próprias impressões sobre aquela criança. Com essa disponibilidade e com um arguto espírito de observação, a autora/analista identifica três diferentes tipos de ensimesmamento vividos pela criança nas sessões e conclui que o momento do "ensimesmamento prazeroso" é o momento adequado para intervir, tentando revelar "uma presença de ser”, ainda que não simbólica (p. 45). Inicia-se, então, um jogo de sons - a repetição, pela analista, dos grunhidos por meio dos quais Maria fazia-se presente -, processo que será longo e que estabelecerá, após vários meses, as condições de possibilidade para a interpretação.

Depois de expor e discutir o relato clínico e antes de dedicar-se ao exame das contribuições da psicanálise à clínica do autismo, a autora aborda a própria noção de autismo, desde sua origem com Bleuler, em 1911, até a descrição, em 1940, por Léo Kanner, da "síndrome do autismo infantil precoce”. Esse assunto é tratado nos capítulos dois e três, por meio de um estudo detalhado da história do conceito de autismo. É impossível transmitir, em poucas palavras, toda a riqueza desse estudo, cujo interesse estende-se ao domínio da história das idéias sobre a psicopatologia. Tentaremos resumir, a seguir, algumas de suas conclusões mais importantes.

O termo autismo foi criado por Bleuler para designar um sintoma secundário da esquizofrenia, isto é, a perda do contato com a realidade e a criação de um mundo imaginário em que o paciente tem todos os tipos de realização de desejos e idéias persecutórias. Esse termo veio do termo auto-erotismo, introduzido por H. Ellis e retomado por Freud. Apesar de reconhecer a importância das descobertas freudianas para a descrição das esquizofrenias, Bleuler propõe o termo autismo, subtraindo eros do auto-erotismo, devido a divergência da escola de Zurich com Freud, no tocante ao papel da sexualidade na determinação das psicopatologias, bem como da vida psíquica de modo geral. Subtraindo-se eros, afastava-se a possibilidade de abordagem dessa manifestação da esquizofrenia pela teoria da libido. No entanto, Bleuler teve o mérito de reconhecer que o pensamento autístico do esquizofrênico não estava diretamente relacionado com o processo mórbido da afecção, o que lhe permitiu ouvir e buscar sentido para o discurso aparentemente ilógico do paciente. Ou seja, o autismo, definido por esse autor, não equivale a um isolamento sem saída, tal como na concepção que será introduzida por Kanner.

Em Kanner o conceito de autismo não somente manter-se-á alijado de eros, mas será também aprisionado em um paradoxo. De forma perspicaz e incisiva, a autora desenvolve, no terceiro capítulo, uma análise crítica que revela esse paradoxo. Vale a pena citar textualmente sua conclusão: 
... a partir da obra de Kanner, o autismo passou a pertencer a dois registros distintos: o de sintoma primordial da doença (autismo extremo) e nome da própria patologia (autismo infantil precoce). E o mais problemático, o autismo deixou de ser uma característica do isolamento e passou a ser o próprio isolamento, signo de um distúrbio orgânico inato. Ao descrever o mundo interno da criança autista como "vazio de pensamentos fantasiosos", Kanner colocou o conceito de autismo em uma situação paradoxal: a criança autista não tem pensamentos autísticos. Ou seja, a criança autista é afetada por um déficit cerebral, o autismo, que a impede não só de entrar em contato com a realidade, como também de fantasiar a realidade. (p. 120)

Ora, a influência de Kanner marca ainda hoje a abordagem do autismo no meio médico e mesmo no meio psicológico, sobretudo entre os cognitivistas que trabalham com a hipótese de que o pensamento da criança autista tem uma evolução deficitária e crônica. Essa visão limita sobremaneira o prognóstico do autismo, uma vez que encontra a barreira orgânica de uma síndrome neurobiológica inata.

Com a publicação, por Melanie Klein, do caso Dick, em 1930, a psicanálise tem seu primeiro registro do tratamento de um caso de autismo. A partir daí, e mesmo após a definição da síndrome por Kanner, muitos psicanalistas tentarão romper a barreira do isolamento autístico e tornar possível o tratamento. Começam a surgir várias contribuições sobre a maneira de interpretar e criar o setting analítico com a criança autista, abrindo uma vertente de pesquisa diferente daquela proposta pelos seguidores de Kanner. Essas contribuições são discutidas por Maria Izabel no capítulo quatro em que se destaca, além do trabalho pioneiro de M. Klein já introduzido no segundo capítulo, os trabalhos de M. Mahler, F. Tustin, D. Meltzer, D. W. Winnicott, J. Hochmann e Laznik-Penot.

Nessa discussão, ressaltamos a parte dedicada à metáfora do "ovo de pássaro", considerada uma "metáfora viva” para referir-se à criança autista, em contraste com as "metáforas mortas" comuns na literatura, tais como "fortaleza vazia”, "concha”, “carapaça”, entre outras. A metáfora do "ovo de pássaro” ou da "casca do ovo" foi utilizada por Freud para descrever o estado da criança nos primórdios da constituição do aparelho psíquico. Se esta metáfora dá margem à concepção de um fechamento autístico originário, a introdução da figura materna nesse ambiente originário, tal como indicada por Freud, muda radicalmente essa concepção. Winnicott irá desenvolvê-la até chegar a afirmar que "não existe um bebê sem os cuidados maternos" (p. 158). Essa metáfora abriu à analista a possibilidade de conceber o ambiente terapêutico como se fosse a casca do ovo, uma casca-holding-sonora que, pouco a pouco, foi substituindo a casca do isolamento autístico de Maria e foi se constituindo em um ambiente fértil, produtor de sentidos (p. 250). Perceber a criança autista como uma metáfora viva produz, 
portanto, uma constante desconstrução de sentidos já estabelecidos e a conseqüente abertura para novas possibilidades de sentido (p. 167).

Constatamos novamente a presença de Winnicott nessas reflexões que preparam o leitor para os capítulos finais, nos quais a autora abordará os elementos que dão sustentação à tese do "analista não intérprete”. "É possível ir além da interpretação?”. É a questão cuja resposta será buscada tanto nos trabalhos dos autores que salientaram a importância do vínculo sensorial não verbal na clínica com a criança autista, entre os quais destacam-se Gilberto Safra e Thomas Ogden, quanto no próprio caso Maria, retomado, em vários de seus fragmentos, para compor um texto em que teoria e clínica se entrelaçam. Como conseqüência necessária dessa reflexão é discutida a função da voz no setting analítico e sua relação com a função dos vocalizes no surgimento da fala.

Concluindo a apresentação desse livro, só podemos repetir que é difícil transmitir, no espaço de uma resenha, toda a densidade e riqueza do texto e convidar o leitor a acompanhar de perto um trabalho que se constitui como um exemplo precioso de investigação psicanalítica, nos vários sentidos que esta expressão comporta.

\section{Referências}

Aulagnier, P. L'apprenti-historien et le maître sorcier - du discours identifiant au discours délirant. Paris: Presses Universitaires de France, 1984. 